\title{
Implementation Strategy of E-government System for Emerging Countries
}

\author{
Yassine Jadi, Lin Jie \\ School of Economics \& Management \\ E-government \& E-commerce Inst. \\ Tongji University \\ Shanghai, China
}

\begin{abstract}
Governments need to play an orchestration role in delivering public services, and the adoption of information and communication technologies is essential to productivity and progress. E-government is unquestionable one of the most critical development system in developing countries, where ICT infrastructure and information society remain the great challenges to overcome. Due to institutional conditions, and compared to developed countries, longer preparation and project time are to be expected when implementing E-government in developing countries. And the delay in implementation of e-government would only cause added cost. In our suggested implementation strategy $G B C$, where Government $(G)$, Business (B), and Citizens $(C)$ are the main player in e-government system, is not necessary to wait for technology to settle in, to be embedded in administrative and bureaucratic process, we adapted existing model and implemented proportionally along with development of digitizing process, with regard to different types of e-government interactions. We call it GBC due to order of implementation strategy.
\end{abstract}

\section{Introduction}

No doubt that academic researchers and governments today have a seem wavelength about definition of electronic government, as the term describe itself and relatively to e-commerce and ebusiness, e-government is the use of information and communication technology (ICT) to improve the relationship between the private citizen and the public sector through enhanced, cost effective, and efficient delivery of services, information, and knowledge. Exclusively as an internet driven activity that improve citizens, access to government information, services and expertise to ensure citizens participation, and satisfaction with government process. More specifically, is the production and delivery of government services through IT applications, used to simplify and improve transactions between government and constituents, business, and other government agencies [1].

Delivering public services and interaction with citizen may not be the priority tasks for government in developing countries, lack of ICT infrastructure, persisting poverty, widespread corruption, and others issue requires handling immediately. We cannot deny the vital of these and other problems, however it's not possible to avoid which is unavoidable, but the delay in implementation would only cause added cost. In fact, launching e-government projects can help to overcome these problems, and strengthening the performance of government public administration, and an efficient and effective state administration is a necessary prerequisite needs for developing countries' economic and social development, it can also delivered four vitals outcomes, constituent satisfaction, government productivity, economic competitiveness and citizen engagement.[2].

The concept of e-government in developed countries should not considered to be automatically appropriate to developing countries, In the implementation of a new ICT-related initiative, the social context, the history and tradition way of doing things within the local organizational context must be taken into consideration. Consequently this implies that the organizations need to have skilled human resources with the ability to creatively adapt new technologies and global practices to the local context and also manage the whole process of implementation. [3]

Our aim is to build a methodology to guide the effective planning of e-government system implementation; we focus specially on the relationship between governments and their entities, organization, business, and their citizens, with regard to digitizing process development.

\section{Literature Overview}

In recent years, the concept of an e-government has attracted a great attention from both researchers and practitioners, from the public administration studies perspective, passing by organization research works, to technology academic research. At the very beginning when the process started in 1994 till today, there are tremendous articles have published on egovernment, there are almost $50 \%$ of e-government studies are either conceptual or data sources for 
analysis, and the other research focused on the geographic location of the studies [4], these researches merely were concentrated on more technological and operational matters and that only more recently attention switched to broadly defined institutional and political issues [5]. A few researches have done for emerging countries, most of them are case studies where building and implementing e-government projects has no a common star up or road map. A recent study by the United Nations has shown that many emerging economies are making positive strides to develop their e-government capabilities [6], e-government adoption in Latin America [7], e-government development in the Caribbean, participatory governance in South Africa [8], and e-government project in Iran [9], are especial cases for egovernment initiatives, and each of these articles contributes to the understanding of e-government by focusing on particular issues related to e-government in specific parts of the world. After we cross academic research works, we come to conclude that there is no discussion of how emerging countries could implement their e-government system base on circumstance of its current state of development.

Tino Schuppan has contributed the solution of real life and development problems in African societies [10], and he argued that the development potential of e-government project can only be realized if certain minimum precondition exists and lack of basic infrastructure needs to be address before a project can be successful undertaken.

\section{Problem Context and Motivation}

When it comes to govern process, each country has its own rules, regulations, and laws, and above all, the culture, but since human society has been experiencing globalization and market liberalization, most countries cannot avoid the impact of such trends, and developing countries with scarce natural resources need to actively cope with such trends for national development.

There are many reports explore the constraints of building e-government system, including those from ITU, UNPAN, UNCTAD, and Accenture. At the beginning and for advanced and emerged countries there was a common barrier to build up and implement e-government projects. Usage, digital divide, ICT infrastructure, and public administration regulation policies were the main factors to deal with. A recent study by Harris compared the ICT situations in six selected developing countries, based on World Bank data for 2000. There are two important technologies, telephone lines and personal computer penetration, for several developing countries, as well as the number of Internet users. An interesting finding is that the developing countries are very non-homogeneous with respect to technology availability and use, differing by two orders of magnitude. Beside the ICT barriers, there is a political administration system in these countries that has a wide impact on E-government projects; in the following we describe in details these two main constraints.

\subsection{Political administration system.}

In emerging democracies worldwide, political parties are too weak, too constrained by oppressive government, or too corrupt and out of touch to earn respect and support of the public. Centralized decision making, the lack of well-institutionalized rules and procedures, and the decline of ideology or unifying principles have eroded public support and discouraged public participants.

The political-administrative category includes the general functional liabilities of politicaladministrative systems as a whole, for example, the low level of democratization. In many African countries, military coups and civil wars make administrative reforms difficult, if not impossible. Another important factor is the experience which a state has making administrative reforms. Observations of E-Government programs have shown that especially those countries which have undergone organizational changes in the direction of public management-oriented reform are better prepared to implement E-Government than countries which do not have such experience. This is especially relevant for African countries because administrative capacities are weakly developed in general and management liabilities cannot be compensated for by the use of technology.

\subsection{Infrastructure/ connectivity}

The ICT infrastructure and connectivity has radically changed the developed world.

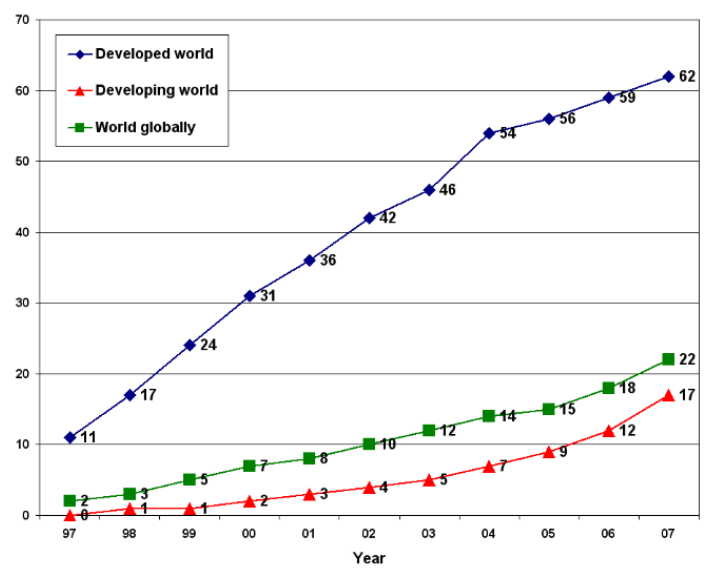

Figure 1. Internet users per habitat 97-07 (ITU source) 
Computing and information technologies now pervade almost every area of life. Information which in the past was difficult or expensive to obtain, is now generally abundant and inexpensive. People living in advanced countries are now more likely to suffer from information overload than information scarcity supporting and enabling the execution of egovernment (see Figure 1).

An e-government infrastructure in general comprises network infrastructure, security infrastructure, application server environment, data and content management tools, application development tools, hardware and operating systems, and systems management platform. However, many developing countries do not have the infrastructure necessary to deploy e-government services, includes internet access and other basic infrastructure, and there is not only the internet access rates issue, but in many rural areas electricity is not available or is only available for a few hours a day [11]. Most of developing countries have more than one language spoken by the populace, and an effective web application in e-government web portals requires standardization a common language in which citizens are comfortable communicating, due to standardization process, the deployment of egovernment system could be longer with added cost. From another side, the studies show that, especially in Africa, the younger-educated classes and men use the internet more frequently, so that in the result could be a one-sided concentration leading to the further systematic exclusion from online services of women and of the lower social classes [12]. However, mobile phone penetration has increased by double-digit amounts in many countries of subSaharan Africa [10], a factor which should be considered when selecting access channels for EGovernment services.

\subsection{Social impact}

In developing countries, the gap between the educated elite and uneducated poor is wide. And for the educated populations those have the necessary resources and have the means to use information and communication technologies are computer literate especially the population from generation $\mathrm{X}$, however the situation would be clearly different for those living in rural areas. This 'digital divide' between those who already have access and those who would not gain access for a long time may result in long-lasting and widening economic gaps between the ICT haves and have-nots. As a result, the provision of e-government services would be biased, favoring educated, urban residents.

\section{Research Question and Objective}

In most emerging countries there are excite several government portals that allow citizens to get informed about a specific ministry's mission and/or administrative structure and points of contact. A few of these portals allow also downloading data and forms. But these portals were not considered as Egovernment system because their primary goal was to inform and not to deliver online services, and each department was operating on their own. The case studies that we have mentioned early have made it clear that when implementing E-government in developing countries, basic processes and services need to be thoroughly established for the long-term and that the optimization of existing projects is less important (morocco digital as case study).

In this research, we are interested in developing a new strategy to guide e-government implementation for developing countries. A few models have been developed to depict e-government stages in the literature [13], [14], [15], [16], [17]. However, there are two major issues with these models. First, these models are developed from difference perspectives. Second, some of the stages in these models either are overlapping or are inconsistent with each other. In order to better understand e-government from an evolving perspective, this paper proposes a comprehensive strategy for e-government implementation for emerging countries based on type of e-government, digitizing process and conceptual analysis.

\section{Methodology}

We conduct our research base on two facts. The first one is we look into the e-government implementation models and extract the model that is more matching to implement it in developing countries with current conditions. And the second fact we base on different categories of e-government interaction to gradually optimize our implementation strategy. Before we get into strategy details, we will discuss e-government implementation models and type of e-government interaction.

\subsection{Models}

A 2001 study of the development of eGovernment by UN identified the level of egovernment in 190 nations (UN/ASPA, 2001).The study outlined five stages of e-government, spanning from emergence to integration. At the time of the survey, none of the surveyed nations had achieved integration, and only 17 had achieved the transaction stage. Most developing nations were either at the emergence or at the broadcast stage, thus providing very few interactive services to their citizens. Table 1 
shows the steps that the five models predict for the development or evolution of e-government.

Table 1. E-Government Implementation Models

\begin{tabular}{|c|c|c|c|}
\hline Models & $\begin{array}{l}\text { Number of } \\
\text { stages }\end{array}$ & Stage & \\
\hline $\begin{array}{l}\text { Hiller's and } \\
\text { ASPA's (2001) }\end{array}$ & Five stages & $\begin{array}{l}1 . \\
2 . \\
3 . \\
4 . \\
5 .\end{array}$ & $\begin{array}{l}\text { Emerging web presence. } \\
\text { Enhanced web presence. } \\
\text { Interactive web presence. } \\
\text { transactional web } \\
\text { presence } \\
\text { Fully integrated web } \\
\text { presence (Hiller, 2001). }\end{array}$ \\
\hline Deloitte's (2001) & Six stages & $\begin{array}{l}1 . \\
2 . \\
3 . \\
4 . \\
5 . \\
6 .\end{array}$ & $\begin{array}{l}\text { Information publishing/ } \\
\text { dissemination. } \\
\text { "Official" two-way } \\
\text { transaction. } \\
\text { Multi-purpose portals. } \\
\text { Portal personalization. } \\
\text { Clustering of common } \\
\text { services. } \\
\text { Full integration and } \\
\text { enterprise transaction. }\end{array}$ \\
\hline $\begin{array}{l}\text { Layne and } \\
\text { Lee's (2001) }\end{array}$ & Four stages & $\begin{array}{l}1 . \\
2 . \\
3 . \\
4 .\end{array}$ & $\begin{array}{l}\text { Catalogue. } \\
\text { Transaction. } \\
\text { Vertical integration. } \\
\text { Horizontal integration. }\end{array}$ \\
\hline Moon's (2002) & Five stage & $\begin{array}{l}1 . \\
2 . \\
3 . \\
4 . \\
5 .\end{array}$ & $\begin{array}{l}\text { Simple information } \\
\text { dissemination (one-way } \\
\text { communication). } \\
\text { Two-way communication } \\
\text { (request and response). } \\
\text { Service and financial } \\
\text { transaction. } \\
\text { Vertical and horizontal } \\
\text { integration. } \\
\text { Political participation. }\end{array}$ \\
\hline Gartner's (2000) & Four stages & $\begin{array}{l}1 . \\
2 . \\
3 . \\
4 .\end{array}$ & $\begin{array}{l}\text { Web presence. } \\
\text { Interaction. } \\
\text { Transaction. } \\
\text { Transformation. }\end{array}$ \\
\hline
\end{tabular}

We have chosen to discuss Layne and Lee's model last because it is somewhat of an outlier compared to the other models [15]. Layne and Lee argue that e-government begins with what they call cataloguing, or the basic provision of mostly static information online. They predict that e-government will then move to a transactional stage. Up to this point, their model is substantially similar to the other models reviewed here. From this point, however, Layne and Lee's model diverges from the other models. It predicts that the third stage of egovernment will be vertical integration, which involves upper and lower levels of government sharing data and information online. The final step in Layne and Lee's model is horizontal integration, which means the sharing of data and information online across departments within governments.

These findings offer some support but also raise important questions about the principal normative models of e-government. The findings support the models in that most local governments have adopted e-government, at least at the basic level predicted by models, and have done so in a very short period of time. The findings raise questions about the models in that they are clearly at odds with the models' predictions that governments will move stepwise toward the adoption of more sophisticated egovernment offerings, moving from information to transactions to integration and ultimately to transformation. This predicted movement is not happening, or if it is, the movement is glacial in its speed if e-government were "evolving" as the models predict, greater numbers of governments would have reported changes, and they would have reported more positive changes. But unfortunately the lack of adaptation general model and implemented base on local resource availability, consequently, more delay and struggling to move to next stage and more cost-added.

\subsection{E-government categories}

The ITU report on e-government for developing countries categorize different types of electronic government based on using ICT to facilitate relationships between government and other stakeholders, the types of relationships are with citizens, business, government, and employees, represented respectively as G2C (Government-toCitizen),G2B Government-to-Business), G2G (Government-to-Government), and G2G (Government-to-Government).

In Table 2, we sum up the four e-government categories 'approaches with their main goals.

Table 2. E-Government Categories

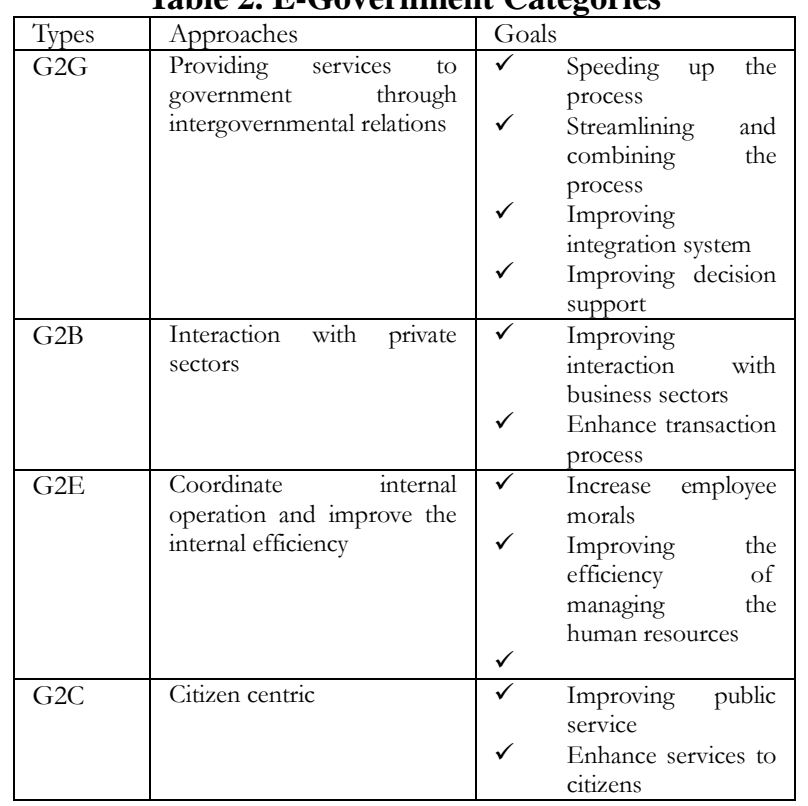

\section{Proposed Implementation Strategy}

In our proposed methodology we considered the model that have been adapted by united nation in 2008 which is classified along five levels are Emerging, Enhanced, Interactive, transactional, and connected. 
At the most basic level, Emerging and Enhanced, e-Government activities focus on publishing basic information on the web. At intermediate levels, Interactive and Transactional, governments use websites to support two-way communication, process transactions online and aggregate content and services through portals. At advanced levels, connected, governments use the web to integrate services across ministries, provide tools for public feedback and deliberation and customize the web visit for each user through personalization technologies and push technologies.

It may need decade to reach full social information and digitizing process has a long road to cross, added to that the policy up-down system regulation. All are the great challenge to cope for building and implementing e-government system. In our implementation strategy, is not necessary to wait for technology to settle in, to be embedded in administrative and bureaucratic process, the implementation of E-government pilot projects should therefore increasingly be building up and implemented base on two factors, digitizing process and policy regulation (see Figure 2).

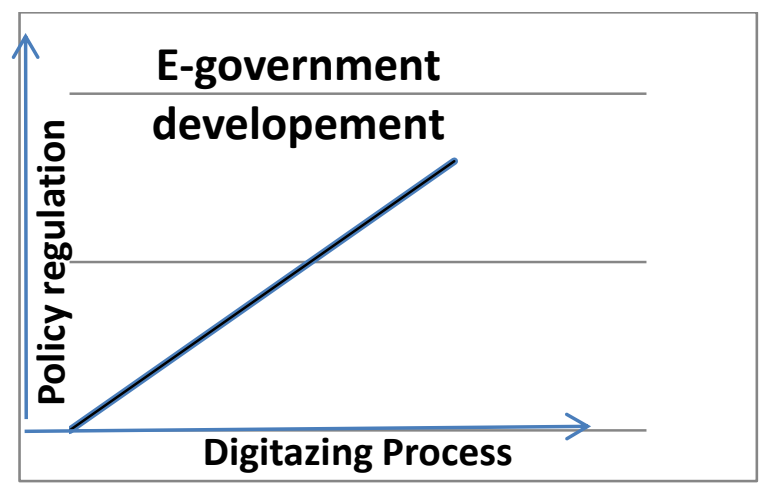

Figure 2. E-government development

Analogically with E-commerce, where the companies firstly builds their portal systems, supported by data base system, interconnection with different departments, application server environment, content management and application development tools, hardware and operating systems, and systems management platform before launching their services and products online. Development of e-government project can be done in seamless way and proportional with digitizing process as well as government interaction, in the following we describe in details how the implementation process should be done.

\subsection{G2G types}

Taking in consideration the resources availability within government organizations, such as intraconnection feasibility, skillful IT employees, and the more important the intergovernmental relations that connect all government stakeholders to coordinate from national, state/provincial, and local government, G2G is the key priority to lunch and develop e-government initiatives for public sector, as they develop their e-government initiatives and establish electronic interaction between government entities and organizations.

In the road of digitizing process we recommend the horizontal development that have been suggested by Layen and Lee at G2G level, where eGovernment activities focus on providing and publishing basic information on the web.

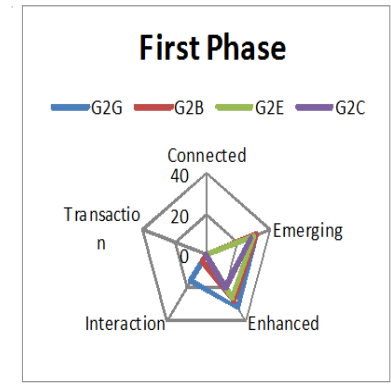

Figure 3. G2G Moved to Interaction stage

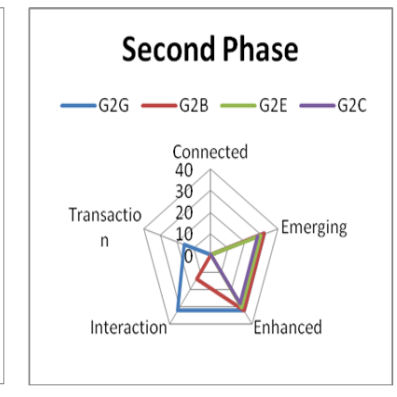

Figure 4. G2G fully interacted
The existing e-government in developed countries, government departments and organizations have maintained separate database that are not connected to other government departments at the same level or even different level such as the local or central government level. This creates barriers between organizations system and process. Emerging counties can avoid these barriers by implementing advanced stage for $\mathrm{G} 2 \mathrm{G}$ while digitizing process ongoing. When the transaction stage is mature for G2G types, it enables the government work properly internal and external, and will be ready to boost other e-government types to move to next stage, G2B, and $\mathrm{G} 2 \mathrm{E}$ to transaction stage, and $\mathrm{G} 2 \mathrm{C}$ to interaction stage (see Figure 3 and Figure 4).

\subsection{G2B type}

In G2B environment, governments and business entities with companies are digitally matured, and because of the large number of purchases that governments make from the private sector, there is a need to develop faster and more cost-effective routines to handle the typical procedures for procurement. The typical tasks include: material planning, sourcing, purchasing and contract management (UNESCAP 2006). Therefore, the G2B transaction stage should primary adapted as soon as G2G become fully integrated (Phase 3). 


\subsection{G2E type}

We name our implement strategy GBC and we did include the alphabet ' $E$ ', because we believe that as soon as $\mathrm{G} 2 \mathrm{G}$ and $\mathrm{G} 2 \mathrm{~B}$ reach advanced stage, there will be a consolidated list of employees for both private and public sectors. This list will gradually be adapted to ICT applications and will be capable of handling procedures of interaction and transaction electronically (See Figure 5 and Figure 6).

\subsection{G2C type}

At the beginning where less advantage segments of the population are less able to access government on the web, the multichannel to government services is the best practice to gradually get citizen to interaction and transaction stage. Other play is if we combine the number of employees for both private and public sectors, we may find it takes more than $60 \%$ of national citizen, so G2B and G2E can dramatically change the number of citizens that be able to interact and make transaction smoothly, as result the $\mathrm{G} 2 \mathrm{C}$ relationship will easily adapted.

Last play is in private sector, customer go according to their own free will, whether someone chooses to go to a company's web site or not is his or her choice, visiting the web or make a purchase is also a matter of choice, but thinking about driving license, born certificate, ID renewal, and other public services, there is only one interaction and only government web portal to require these services. In order to save time and cost, the government can use last play to enhance citizen to move to transaction stage.

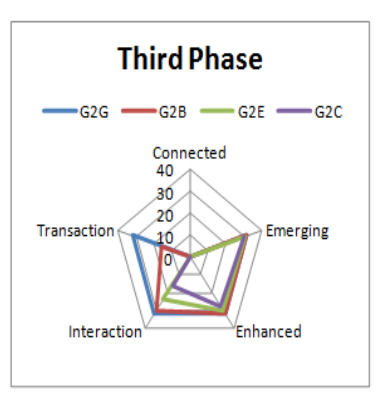

Figure 5. G2B fully interacted

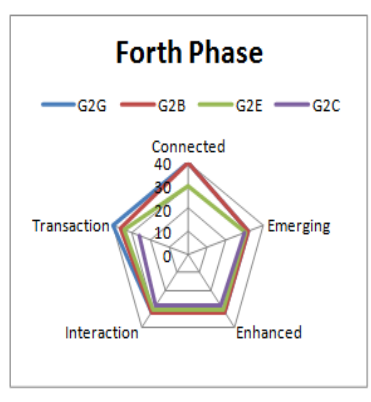

Figure 6. G2G fully connected
Developing G2G system and applications as a way to deliver G2B, G2E, and G2C services seems to occur when many government entities or organizations are required to complete a particular transaction for Business and citizens. In order to provide online application for business or citizens, two or more government entities needed to connect their business processes to allow multiple databases to interact and in some cases accept or disburse fees appropriately. Once the government entities can interact with each other they can offer citizens or businesses access to the application, submit information, make transaction, and receive the service.

Finally, e-governments would reach connected stage where departments collaborate in significant ways to avoid duplication of efforts, and a one-stop contact point is created, which is capable of handling procedures of all involved departments. In this phase when all information systems are integrated and the public can get G2B, G2E, and G2C services at one (virtual) counter. One single point of contact for all services would be the ultimate goal (see Figure 7).

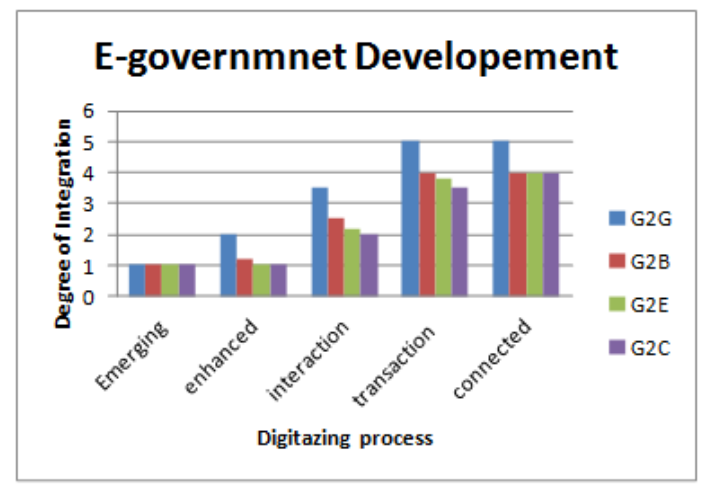

Figure 7. E-government system at mature stage

At this stage, the cost savings, efficiency and customer satisfaction are reaching highest possible levels.

\section{Conclusion}

In the view of the present difficulties facing many developing countries, E-government offers numerous opportunities to overcome those difficulties and improve public services in many areas such as statistical and information processes, finances management, tax systems, public participation and formalization. One of the key issues for developing countries governments is how to manage the process of learning about new technologies and finding appropriate ways of implementing the technology to support its e-Government systems. The feasibility of having a successful e-government is directly depended on the governments' overall ability and readiness to spend on the necessary information technology and related costs. To provide a better understanding of the affordability, the government in developing countries needs to lunch e-government initiatives gradually, starting by the shareholders who has adapted ICT early. Preparing interaction and transaction stages before getting in interaction with 
business G2B and citizen G2Cwill serve the initiatives in better way.

Developing Countries can consider GBC implementation strategy as road map to lunch their egovernment projects initiatives, and adapted in the way could match the current condition for each countries. As result we will have e-government system that could adapted to local conditions, and will be able to learn from it own ongoing process to achieve better e-government system.

\section{Acknowledgements}

We are grateful to all colleagues for their comments and suggestions to earlier version of this paper. Any mistakes or omissions are the sole responsibility of the authors. This study was conducted as part of the $\mathrm{PhD}$ thesis. An earlier version of this paper was presented at the i-Society 2014 London conference proceedings.

\section{References}

[1] M.H. Sprecher, "Racing to e-government: using the internet for citizen service delivery". Government Finance Review, 16 (5) (2000), pp. 21-22

[2] Accenture, 2010 IT Report: "Meet the Global Team Driving High Performance IT", http://www.accenture.com/ us-en/Pages/insight-cio-2010-it-report-summary.aspx

[3] Macome, E., (2003) "On the implementation of an information system in the Mozambican context: The EDM case". In M. Korpela, R. Montealegre, and A. Poulymenakou(Eds.), Proceedings of the International Federation of Information Processing, IFIP9.4 and 8.2 Joint Conference on Organizational Information Systems in the Context of Globalization (pp. 169-184) Dordrecht, The Netherlands: Kluwer.

[4] Rhoda C. Joseph, (2013) "A structured analysis of egovernment studies: Trends and opportunities"

[5] A. Savoldelli, Cristiano C., Gianluca M., "Understanding the e-government paradox: Learning From literature and practice on barriers to adoption”. 2014

[6] Lau, T. Y., Aboulhoson, M., Lin, C., and Atkin, D. J. (2008). "Adoption of e-government in three Latin American countries: Argentina, Brazil and Mexico". Telecommunications Policy, 32(2), 88-100

[7] Joseph, R. C., and Jeffers, P. I., (2009) "E-government maturity in the Caribbean nations". Journal of Global Information Technology Management, 12(1), 52-70.

[8] Twinomurinzi, H., Phahlamohlaka, J., and Byrne, E. (2012). "The small group subtlety of using ICT for participatory governance: A South African experience". Government Information Quarterly, 29(2), 203-211.

[9] Sharifi,M.,andManian, A. (2010). "The study of the success indicators for pre-implementation activities of
Iran's e-government development projects". Government InformationQuarterly, 27(1), 63-69.

[10] Tino Schuppan, 2009 "E-government in developing countries: Experiences from sub-Saharn Africa"

[11] Jensen, M., (2003). "The current status of information and communications technologiesin Africa. In J. O. Okpaku (Ed.), Information and communications technologies forAfrican development". An assessment of progress and the challenges ahead (pp. 55-78).New York: United Nations ICT Task Force

[12] Nakafeero, A., (2005)."Women and ICTs in Uganda: bridging the gender digital divide". InJ. Hellström (Ed.), ICT - a tool for poverty reduction? Challenges for developmentcooperation (pp. 27-32). Uppsala: The Collegium for Development Cooperation.Uppsala University

[13] Hiller, Janine, and France Bélanger. 2001. "Privacy Strategies forElectronic Government". E-Government Series. Arlington, VA: Pricewater house Coopers Endowment for the Business of Government

[14] DeloitteandTouche, 2001. "The Citizen As Customer". CMA Management, Dec2000/Jan2001, 74(10): 58.

[15] Layne, K, and Lee, (2001). "Developing a Fully Functional E-Government: A Four Stage Model". Government Information Quarterly, 18(2), 122-136.

[16] Moon, M. Jae, (2002) "The Evolution of EGovernment Among Municipalities: Rhetoric or reality?" Public Administration Review62(4): 424-433

[17] Baum, C. and A. Di Maio, 2000. "Gartner's Four Phases of EGovernmentModel, Gartner Group, Research Note", http://aln.hha.dk/IFI/Hdi/2001/ITstrat/

Download/Gartner_eGovernment.pdf Accessed October 5, 2003. 